\title{
A Strategy for Development of Realistic Mathematical Models of Whole-Body Metabolism
}

\author{
Mads F. Madsen ${ }^{\#}$, Sune Danø ${ }^{\#}$, Bjørn Quistorff \\ Department of Biomedical Sciences, University of Copenhagen, Copenhagen, Denmark \\ Email: *bqui@sund.ku.dk
}

Received January 17, 2012; revised February 15, 2012; accepted February 26, 2012

\begin{abstract}
When realistic mathematical models of whole body metabolism eventually become available, they are likely to add entirely new dimensions to the understanding of the integrated physiological function of the organism, in particular the mechanisms governing the regulation of transitions between different physiological states, like fed-fasted, exercise-rest and normal-diseased. So far the strategy for whole body modelling has primarily been a bottom-up approach where the central problem is an apparently insurmountable barrier of complexity involved in defining and optimising the huge number of parameters. Here we follow a top-down strategy and present a complete mathematical framework for realistic whole body model development. The approach proposed is modular and hierarchical and whole body metabolism is taken as the top level. Next are the organs, where the sum of the contributions from the individual organs must equal the top level metabolism. This hierarchy can be extended to lower levels of organisation, i.e. clusters of cells, individual cells, organelle and individual pathways. Exploiting this hierarchy, metabolism at each level forms an absolute constraint on the contributions from lower level. Importantly, these constraints can in many ways be defined experimentally through mass balance and flux data. Furthermore, the constrained approach allows the lower level models to be developed independently and subsequently adapted to the whole body model. The paper describes the process of whole body modelling in practical terms, centred on a mathematical framework, devised to allow whole-body models of any complexity to be developed. Furthermore, an example of sub-model incorporation in the whole-body framework is illustrated by adapting an existing erythrocyte model to the whole body constraints. Finally, we illustrate the operation of the system by including two sets of whole-body data from humans, reflecting two different physiological states.
\end{abstract}

Keywords: Whole Body Metabolic Modelling; Organ Interaction; Mathematical Modelling

\section{Introduction}

The development of mathematical models that can describe the overall metabolism of a human will not only be a milestone for biosimulation but is also likely to add completely new dimensions to the understanding of the dynamics of the integrated metabolic and physiological function in health and disease.

The human and other mammalian organisms are naturally compartmentalised, composed of a number of organs with specialised physiological and metabolic functions. Similarly, the organs are composed of several types of cells, often with sub-populations which are specialised to perform specific tasks, like the perivenous hepatocytes, which exclusively perform the glutamine synthesis of the liver [1]. Thus, from a modelling point of view, it is important to realize that the body and the organs work in a modular, but concerted, manner. A well-known example of concerted action at the organ level is the interplay be-

${ }^{*}$ Corresponding author.

"Present Address: Topsoe Fuel Cell, Lyngby, Denmark. tween the liver and muscle, termed the Cori cycle, where the muscle delivers lactate and alanine to the liver, which converts lactate to glucose and alanine to urea plus glucose. Subsequently, the glucose may return to the muscle as energy substrate [2]. Another more recently observed organ-organ interaction is the functional coupling between brain and muscle, where lactate derived from the muscles during intense exercise is used extensively by the brain as a supplement to the normal substrate, glucose [3]. Analogously, during fasting the liver produces significant amounts of ketone-bodies which are excellent substrates for the brain and heart $[4,5]$.

The key outcome of whole-body metabolism modelling will be the piecing together of fragmented biochemical and physiological information to an integrated understanding of the overall metabolic function, and in particular the possibility to interrogate the model about dynamic aspects of metabolism, which for practical reasons are very difficult or impossible to approach experimentally. Thus, whole-body models will allow testing of 
hypotheses about the complicated regulatory mechanisms that govern metabolic flows, and allow the study of transitions occurring when the body switches from one mode of operation (a physiological state) to another, e.g. during the transition from rest to exercise, from the fed to the starved state, and indeed from a normal to a diseased state. In particular, this can be expected to provide crucial information about dysmetabolic conditions such as type 2 diabetes [6,7] and the intimate involvement of mitochondrial metabolism of this disease [8].

Mathematical models of metabolism have so far mainly been targeted at relatively small sub-networks in the individual cells, like for example erythrocyte metabolism $[9,10]$ or the cell cycle machinery [11]. Even at this intracellular level there is extensive modularity in the form of subcompartments like the mitochondria, the nucleus, the Golgi apparatus, the endoplasmic reticulum, etc. This modularity has been observed and utilized extensively by researchers working to establish models of the individual cells, or analyse their behaviour. Examples of such modular approaches are modular kinetic analysis [12-14] and modular control analysis [15-17]. It is very likely that the application of these methods could provide a good basis for guiding modelling and experimentation, also in the context of whole-body modelling. There are some examples of modelling at the wholebody level like pharmacokinetic studies describing the uptake, conversion, and excretion of drugs [18] and pharmacokinetic modelling where drug metabolism at the whole-body level was elucidated $[19,20]$. Several models of type 2 diabetes, of varying complexity, have also been developed [21,22], and multi-organ models have been used in the study of amino acid metabolism $[23,24]$. Also, minimal whole-body models have proven useful for interpreting the result of glucose tolerance tests, but are of a very abstract character, often containing no more than a few variables [25]. A recent approach exploits the fact that glucose and insulin flux estimates can be obtained from experiments using minimal modelling in conjunction with isotope labelled glucose [26]. These flux estimates can be used to perform parameter estimation on submodules of the whole system using a forcing approach [27]. Another purely top-down approach to modelling of whole-body metabolism has been attempted recently [28]. Models of the heart have been constructed bridging several levels of complexity [29]. While these models have been successful in describing the pumping function of the heart, their integration in a whole-body context is lacking.

In principle, a whole-body model could be constructed simply by assembling models of all the individual processes involved. This is often the modelling strategy pursued in engineering, like for example robotics [30]. However, the reality of biochemical systems is that most quan- titative aspects of the processes and regulatory systems are unknown at the molecular level, as is also the exact conditions in vivo under which they are operating. This makes modelling of whole-body function according to a strict bottom-up approach impractical. Even if enough information was available about relevant individual pathways, the assembling of the necessary, very large amounts of data is not likely to produce a whole-body model that mimics the actual observed overall human physiology. It would seem that this was the lesson learned from the "silicon cell" approach, where models constructed according to this approach could not be made to work appropriately [31-34] - as examined in [33] one is often required to change in vitro enzyme activities many fold in order to mimick in vivo behaviour of yeast glycolytic fluxes. One likely reason for these difficulties is the inevitable accumulation of errors, which will arise during the measurement of the individual parts of the system. Another potential source of problems is the transferability of in vitro measurements to in vivo conditions [35-37]. One might plan on improving the performance by extensive parameter optimisation. However, as illustrated in Figure 1, the huge number of parts and parameters in such a model will lead to a combinatorial explosion that will render the task of parameter fitting very difficult, if not impossible. On the other hand, the silicon-cell approach has the great advantage of building directly on a vast amount of biochemical knowledge. This sets out a straight-forward, rational, method for formulating biochemically realistic model structures. It also allows the modeller to apply standard biochemical methods and data that would have to be discarded with a strict top-down modelling strategy. Consequently, an optimal modelling strategy would combine the best sides of the top-down and silicon cell approaches, and lend from the developments of modular approaches already utilized in the modelling community, in for example engineering where hierarchical modelling has been applied successfully for years [30,38,39]; the purpose of the present paper is to propose such a strategy.

One of the top-down aspects of our strategy is that each dynamic organ model is constrained by net metabolic changes across the organ as defined by arteriovenous differences observed experimentally. Another is that the sum of the model outputs of all organs must equal the total turn over of the whole body. Similarly, the individual organ model can form absolute constraints for the modelling of the cells making up the organ. This principle of constraint can be applied recursively to individual organelles within cells as illustrated in Figure 1. This procedure complements the silicon-cell approach by circumventing the problems of error accumulation encountered here, and ensures an over all realistic model behaviour in the predefined physiological state. The bottom-up aspect of the strategy is that the complexity of the 


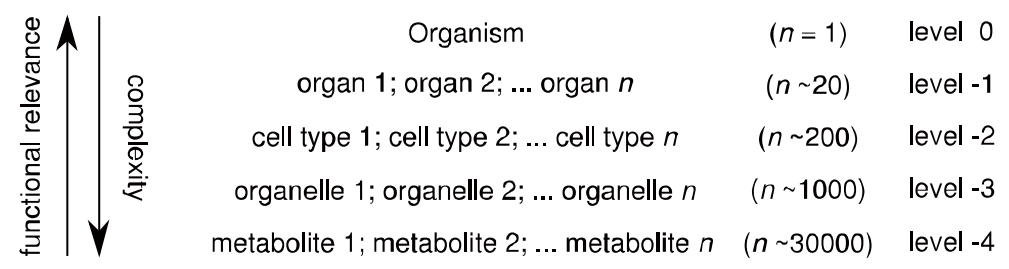

Figure 1. Hierarchical organisation of the body. The number of distinct components increases exponentially when a description of the body is made at lower levels of organisation: $n_{\text {celltypes }} \approx 10 \cdot n_{\text {organs }} ; n_{\text {organelles }} \approx 5 \cdot n_{\text {cell types }} ; n_{\text {metabolites }} \approx 30 \cdot n_{\text {organelles }}$. Hence, complexity increases and the functional relevance of each component decreases accordingly.

individual organ models can be chosen at will, so that any available silicon-cell model can be included in the metabolic whole body model. In essence, the top-down constraints act like "the cement" that combines individual silicon-cell building blocks.

In practical terms, the modelling strategy developed in this communication, exploits the natural compartmentation into organs to facilitate parameter estimation: The integrated function of each individual organ can in principle be studied in vivo by applying the Fick principle [40] by multiplying arterio-venous concentration differences with blood flow across the organ. This experimental approach has been applied extensively in the study of organ physiology in the past and more recently also to study of brain energy metabolism as well as muscle-brain interactions providing data on the global metabolism of the human brain in vivo [41-43] at a time resolution of less than five seconds [44]. Combined with stable isotope infusion to the subject during the experiment yet another level of information on the dynamics of metabolism may be obtained [45].

In this paper a formalism that allows this kind of modular, constrained metabolic whole-body modelling to be performed, is presented. Its use is illustrated on metabolic data describing two well-defined physiological states, fed and fasted. Finally, the mathematical tools for adapting specific organ models as modules of the whole-body model are presented.

\section{The Modelling Framework}

The whole-body model is a set of ordinary differential equations describing the dynamics of a large number of metabolite concentrations in many different, specific locations of the body. The whole-body model consists of dynamic modules, the organ models, which are connected metabolically by connecting compartments, typically the blood and the interstitial compartments. The modules are the anatomical entities, heart, liver, brain, kidney etc, but also more disperse structures like the erythrocytes are treated as an organ. The connecting compartments are assumed to be metabolically inert, although this may not be strictly correct. An example of how a whole-body model may be structured is shown in Figure 2(d).

Below we introduce the nomenclature, the mathemati- cal structure of the model, and the specific constraints on both level 0 (whole organism; cf. Figure 1) and level -1 (individual organs).

\subsection{Definitions}

For each of the organ models, the chemical amounts inside organ $i$ is denoted by the vector $\mathbf{m}_{i}$. The time evolution of chemical amounts in organ model $i$ is described by the set of ordinary differential equations, $\mathrm{d} \mathbf{m}_{i} / \mathrm{d} t=\mathbf{f}_{i}$. An example of the organs that could be described by $\mathbf{f}_{i}$ and $\mathbf{m}_{i}$ is given in Figure 2(a).

The organ models interact through the connecting compartments as illustrated by ellipses in Figure 2(b). The chemical amounts in these connecting compartments are denoted by the matrix $\mathbf{n}$. Rows correspond to chemical substances, columns to compartments. Chemical substances can be everything from ions, over metabolites to signalling molecules; in the remainder of the article, we will refer to this broad class of substances as "metabolites". The dimension of $\mathbf{n}$ is $M \times C$, where $M$ is the number of metabolites that are present in the connecting compartments, and $C$ the number of such compartments. The constant matrix $D_{t} \mathbf{n}^{\sigma}$ has the same structure, and contains the experimentally determined rates of change of metabolite $m$ in the connecting compartment $c$ in the physiological state $\sigma$.

To keep track of the connections between organ models and connecting compartments, we introduce $\mathbf{D}_{i}$, the $(C+1) \times C$ exchange matrix. This matrix is constructed from the identity matrix; diagonal elements, which correspond to compartments that have no physical contact to organ $i$, are changed to zeros. The matrix is finally augmented with a single row of zeros, to eliminate the storage subset of $\mathbf{b}$ (see below). These connections between organ models and connecting compartments are illustrated in Figure 2(c). The definition of connectivity is purely technical in nature; it is only taken into account during the construction of the organ models. The actual mass flows between organ model $i$ and the connecting compartments is contained in the $M \times(C+1)$ matrix function $\mathbf{b}_{i}$. The elements of $\mathbf{b}_{i}$ are the transport and storage subset of $\mathbf{f}_{i}$, i.e. a reordering of the elements corresponding to reactions crossing the boundary between 
organ and connecting compartment. The extra compartment column keeps track of the build up or depletion of storage compounds in the organ model. The constraints on the fluxes that the functions $\mathbf{b}_{i}$ have to fulfil are given in $\mathbf{b}_{i}^{\sigma}$, of identical dimension. $\sigma$ refers to a specific physiological state.

Due to the anatomical organisation of in- and out-flow to an organ there can be no uptake from the venous compartment and, likewise, no excretion to the arterial compartment. Blood flow directions thus create another technical constraint to be taken into account during the construction of an organ model. This direction of flow is shown as arrow heads in Figure 2(d). The information is contained in $\tilde{\mathbf{D}}_{i}$, the $(C+1) \times C$ flux direction matrix.
The matrix has the same structure as $\mathbf{D}_{i}$, but both reversible reactions and missing reactions have a zero diagonal element. If there is only inflow from a compartment, the diagonal element is changed to -1 , if there is only outflow it is left unchanged. Example 1 in the discussion illustrates the definitions introduced above.

\subsection{Model}

A whole-body model takes the form of a set of ordinary differential equations, ODEs, describing both the time evolution of the chemical amounts of the metabolites being exchanged between the organs and/or the surroundings through the connecting compartments, as well as internal conversions inside individual organs: (a)

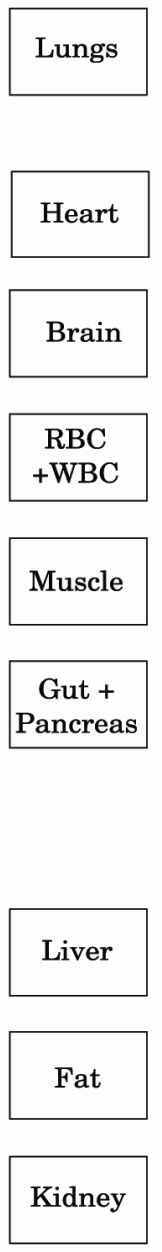

(b)

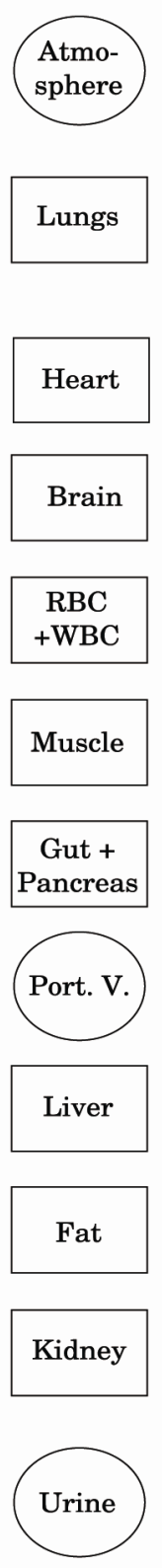

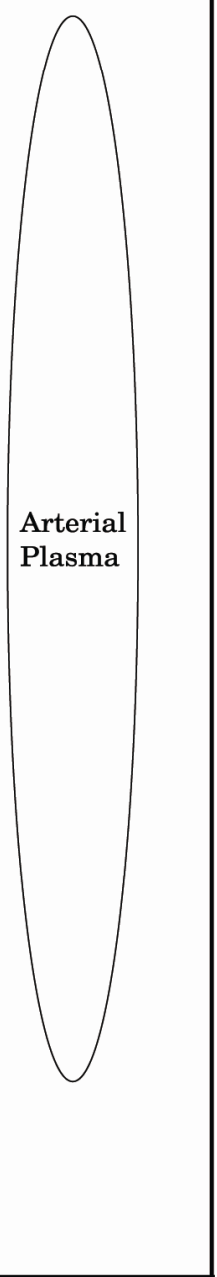




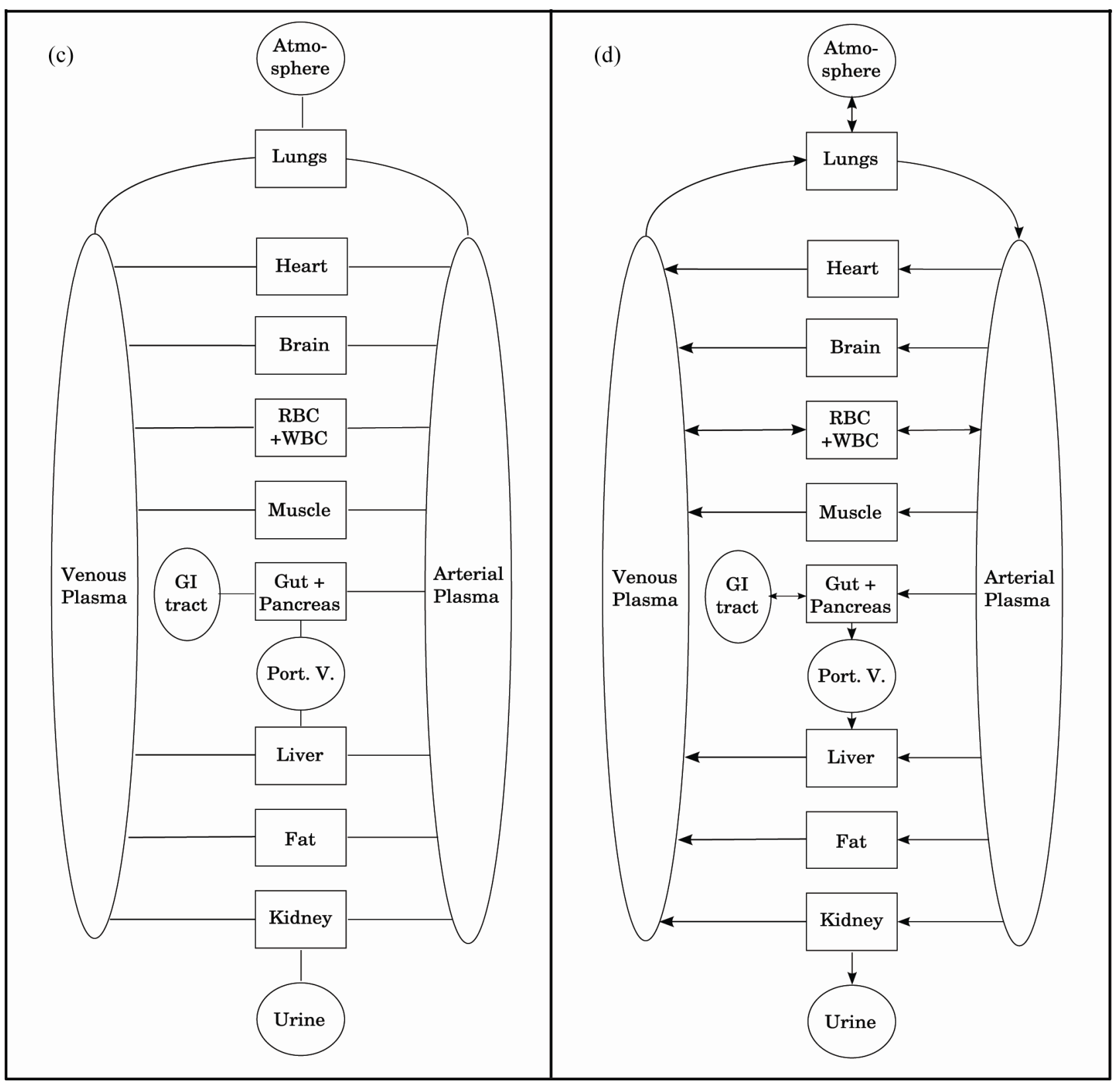

Figure 2. Structure of a whole-body model with classes of structural elements being added from a to d. Boxes indicate organ models (a)-(d), ellipses indicate connecting compartments (b)-(d), lines between boxes and ellipses indicate connections (c)-(d), and arrows indicates mass flow directions (d). The dynamics of each organ is described by a kinetic model, and these organ models are coupled via the connecting compartments. GI tract, gastrointestinal tract; Port. V., portal vein; RBC, red blood cells; WBC, white blood cells.

$$
\begin{aligned}
& \frac{\mathrm{d} \mathbf{n}}{\mathrm{d} t}=\sum_{i=\text { organs }} \mathbf{b}_{i}\left(\mathbf{m}_{i}, \mathbf{n}\right) \mathbf{D}_{i} \\
& \frac{\mathrm{d} \mathbf{m}_{i}}{\mathrm{~d} t}=\mathbf{f}_{i}\left(\mathbf{m}_{i}, \mathbf{n}\right) .
\end{aligned}
$$

Thus, a whole-body model is composed of a set of submodels, each describing the metabolic function of an organ. The whole-body model is obtained by describing the interactions between these organ models via the con- necting compartments. The dynamics of the body's overall metabolism is simulated by numerical integration of Equation 1.

\subsection{Constraints}

In order to insure that the whole-body model yields physiologically realistic simulations of a chosen physiological state $\sigma$, we establish the following constraint on the model at level 0 : 


$$
\frac{\mathrm{d} \mathbf{n}}{\mathrm{d} t}=D_{t} \mathbf{n}^{\sigma}=\sum_{i=\text { organs }} \mathbf{b}_{i}^{\sigma} \mathbf{D}_{i} .
$$

In other words, the concentrations of the metabolites in the connecting compartments (the ellipses in Figure 2) should change at fixed rates that match the experimental observations in the physiological state $\sigma$.

In addition, it is required that the functions of the individual organ models match reality. This means that their input-output relations must fit the experimental determinations. These functional organ constraints are given by

$$
\mathbf{b}_{i}^{\sigma}=\mathbf{b}_{i}\left(\mathbf{m}_{i}, \mathbf{n}^{\sigma}\right),
$$

i.e. there should exist an $\mathbf{m}_{i}$ such that the rates of metabolite transport and storage buildup match the measured values in the physiological state $\sigma$. An example of functional organ constraints is given in Section 3.4, Example 2.

In addition to these nontrivial constraints on the behaviour of the individual organ models, we impose the following technical constraints on $\mathbf{b}_{i}^{\sigma}$ and $\mathbf{b}_{i}\left(\mathbf{m}_{i}, \mathbf{n}\right)$, which are based on blood flow direction and spatial organisation of the organs in the blood circulation. Uptake by an organ can only occur from the in-flowing blood and vice versa for the out-flowing blood,

$$
\begin{aligned}
& \mathbf{b}_{i}^{\sigma} \tilde{\mathbf{D}}_{i} \geq \mathbf{0} \\
& \mathbf{b}_{i}\left(\mathbf{m}_{i}, \mathbf{n}\right) \tilde{\mathbf{D}}_{i} \geq \mathbf{0} \text { for all } \mathbf{m}_{i}, \mathbf{n} .
\end{aligned}
$$

Also, no organ model should exchange metabolites with connecting compartments, with which it is not physically connected:

$$
\begin{aligned}
& \mathbf{b}_{i}^{\sigma}\left(\mathbf{I}-\mathbf{D}_{i}\right)=\mathbf{0} \\
& \mathbf{b}_{i}\left(\mathbf{m}_{i}, \mathbf{n}\right)\left(\mathbf{I}-\mathbf{D}_{i}\right)=\mathbf{0} \text { for all } \mathbf{m}_{i}, \mathbf{n} .
\end{aligned}
$$

\subsection{The Process of Model Development}

The two main tasks of whole-body model construction are the experimental determination of functional organ constraints $\mathbf{b}_{i}^{\sigma}$, and the adaptation of organ models $\mathbf{f}_{i}$ to these functional organ constraints. Once an organ model has been adapted to the functional organ constraints, it can be plugged into the corresponding whole-body model, and the whole-body model is operational when all the organ models specified in the whole-body model structure have been plugged in.

As indicated above, the functional organ constraints are calculated from simultaneous measurements of the blood flow and the concentration differences between arterial and venous blood across an organ in each of the specific physiological states $\sigma$. For each of these states, the resulting functional organ constraints must be internally consistent in terms of mass balances, i.e. Equation 2 should be fulfilled.
The adaptation of an organ model to measured metabolite fluxes is a non-trivial problem of constrained optimisation, where the constraints are given by Equation 3. We demonstrate the feasibility of this crucial step in the following section, where we give two explicit suggestions for adaptation of organ models to functional organ constraints. Our approach is related to that of [46] and [34].

\subsection{Matching the Fluxes of an Organ Model to a Specific Physiological State}

We propose a flux-matching strategy based on the formalism of extreme currents, which provides an efficient way of describing all possible steady state fluxes in a chemical reaction system. See chapter II, Section C in [47] for details. The kinetics of a chemical reaction system is generally given by $\mathrm{d} \mathbf{m} / \mathrm{d} t=\mathbf{f}=\mathbf{v} \cdot \mathbf{v}$, where $\mathbf{v}$ is the stoichiometric matrix of the reaction network, and $\mathbf{v}$ is the velocity vector, which indicates the velocities of each of the reactions in the network. As before, $\mathbf{f}$ is the organ model and $\mathbf{m}$ is the vector denoting the chemical amounts inside the organ. (Note that the organ-denoting indices $i$ have been left out, as we here deal with a single organ at a time.) The possible steady states of the reaction network can be found as the null space of $v$, i.e. the space of all vectors $\mathbf{v}$ for which $\mathbf{f}=\mathbf{v} \cdot \mathbf{v}=\mathbf{0}$. We will match the organ model to the flux matrix $\mathbf{b}^{\sigma}$ at such a steady state; this steady-state constraint is more restrictive than the constraint imposed by Equation 4, since strict stationarity is required for all non-storage metabolites in the organ.

Geometrically, the part of velocity space where $\mathbf{v} \cdot \mathbf{v}=\mathbf{0}$ is a polygonal cone (colloquially: an inverted pyramid of infinite height) extending from origo, and it is generally of lower dimension than the velocity space. This steady-state part of velocity space is known as the current cone, and the velocity vectors defining the edges of the cone are known as the extreme currents ("current" is short for steady-state velocity). Any steady state velocity vector $\mathbf{v}$ can be represented by a point in the current cone and expressed as a "convex combination", or linear combination with non-negative coefficients $j_{k}$, of the extreme currents $\mathbf{E}_{k}$ :

$$
\mathbf{v}=\sum_{k} j_{k} \mathbf{E}_{k} .
$$

This representation need not be unique, however.

The functional organ constraints in the matrix $\mathbf{b}^{\sigma}$ only define the input-output relations of the organ model, so many different steady-state flux distributions $\mathbf{v}$ will match. For each reaction $r$ in $\mathbf{v}$ matching an element of $\mathbf{b}^{\sigma}$, the combined steady state and functional organ constraints are given by:

$$
b_{r}^{\sigma}=\sum_{k} j_{k} E_{k, r}
$$


where $E_{k, r}$ are the elements of $\mathbf{E}_{k}$. If the constraint cannot be met, then this implies that the reaction network (the "stoichiometry") of the organ model makes it impossible to have a steady state with the input-output relations imposed by the functional organ constraints, and the network must be changed accordingly.

The constraint is linear. If a quadratic optimisation criterion is given, then the efficient method of convex quadratic programming can be used to find a global optimum [48]. The optimisation criterion $\mathcal{F}$ would typically express how close the steady-state flux $\mathbf{v}$ of the modified organ model is to that of a particular steady-state flux $\mathbf{w}$ in the original organ model, e.g. $\mathcal{F}=\sum_{k}\left(K \frac{v_{k}}{w_{k}}-1\right)^{2}$ with $K>0$. If $K$ is included in the parameter optimisation, then this objective function defines the optimal steady-state as the one with the smallest relative flux changes compared to the original model, i.e. the flux distribution pattern is preserved while the flux magnitudes are allowed to change. If, on the other hand, $K$ is fixed at $K=1$, then the optimal steady state is the one with the smallest absolute flux changes compared to the original model. Example 2 in the discussion illustrates the use of the flux-matching strategy presented above.

\subsection{Fixing an Organ Model at Its Optimal Steady-State Flux}

Once an optimal steady-state flux has been found, it must be ensured that the kinetics of the organ model allows it to operate at this steady-state flux. This can be done in several ways; we will now indicate a particularly simple one [46].

The rate of a chemical reaction $r$ can be written as $v_{r}=\kappa_{r} g_{r}\left(\mathbf{c}, \mathbf{K}_{r}\right)$ where $\kappa_{r}$ is the velocity parameter of the reaction, $\mathbf{K}_{r}$ is a vector containing the intrinsic parameters of the reaction (i.e. all remaining parameters), and $\mathbf{c}$ is the concentration vector given by $\mathbf{m}$ and $\mathbf{n}$. The splitting of the parameters into velocity parameters and intrinsic parameters makes it straight forward to fix a model at a particular steady-state flux $\mathbf{v}$ and a particular set of concentrations c, which we want to become steadystate concentrations of the modified organ model. For each reaction, the velocity parameter is now given by $\kappa_{r}=v_{r} / g_{r}\left(\mathbf{c}, \mathbf{K}_{r}\right)$. Operationally, this corresponds to adjusting the enzyme activities ( $V_{\max }$ values) of the organ model, so as to meet the fluxes of the optimal steady state. The use of the method is exemplified in 3.4, Example 2.

\subsection{Adapting an Organ Model to Multiple Physiological States}

For multiple physiological states, the problem is essentially the same as above, only now, instead of a single set of transport matrices, we use several sets of $\mathbf{b}^{\sigma}$. In the different states, internal chemical amounts $\mathbf{m}_{i}$ will in general be different, but parameters $\kappa_{r}$ and $\mathbf{K}_{r}$ are required to be the same between states.

With several physiological states the problem can, in general, no longer be solved by adjusting only the velocity parameters $\kappa_{r}$, so the method must be expanded to include all parameters $\mathbf{p}$ and concentrations $\mathbf{c}^{\sigma}$ in the system.

As before, each state, $\sigma$, gives a set of constraints on the convex coefficients in the corresponding state:

$$
b_{r}^{\sigma}=\sum_{k} j_{k}^{\sigma} E_{k, r} \quad j_{k}^{\sigma} \geq 0
$$

for all states, $\sigma$, and elements of $\mathbf{b}, b_{r}$. In addition, the individual rate expressions must match the flux-distribution:

$$
v_{r}\left(\mathbf{c}^{\boldsymbol{\sigma}}, \mathbf{p}\right)=\sum_{k} j_{k}^{\sigma} E_{k, r} .
$$

The optimisation would typically be done using the objective function

$$
\mathcal{F}=C_{\text {par }} \sum_{k}\left(\frac{p_{k}}{p_{k, \text { orig }}}-1\right)^{2}+C_{\text {met }} \sum\left(\frac{c_{k, \sigma}^{\sigma}}{c_{k, \text { orig }}^{\sigma}}-1\right)^{2},
$$

where $p_{k \text {,orig }}$ are the reference parameters, $c_{k, \text { orig }}^{\sigma}$ are the reference concentrations, and $C_{\mathrm{par}}$ and $C_{\text {met }}$ is a set of user-defined weights that determines the relative importance of the different classes of data.

Equations 11 are now nonlinear, and this might render the optimisation problem computationally very demanding. It is, however, possible to reduce the optimisation problem to a polynomial programming problem if certain parameters are not included in the optimisation - in the typical case, Hill coefficients would need to be excluded from the optimisation, but $V_{\max }$ parameters, $K_{\mathrm{M}}$ parameters and $\mathbf{c}^{\sigma}$ vectors could be included. If the optimisation is performed in this way, the global optimum can always be found $[49,50]$.

\section{Discussions}

We have developed a mathematical formalism that allows for realistic modelling of whole-body metabolism of any complexity. The formalism takes the form of a modelling framework, where models are established by a top-down approach designed to encompass detailed biochemical sub-models, which are typically constructed by a bottom-up silicon-cell like process [31-34]. A key feature of our approach is the exploitation of the natural modular structure (individual organs) of the body, which communicates in terms of chemical mass flux via connecting compartments, primarily the blood. The mass flux between organs is considered in terms of uptake, release and storage of substrates and products of metabolism, including inorganic ions. Other humorally transmitted 
substances like hormones and other signaling molecules can also be included on the same level as other substances. This structure of the framework also provides a realistic means of collecting the necessary experimental data at the organ level as arterio-venous concentration differences. To complete the experimental data sets it is also necessary to have organ blood flow information in order to quantify the net mass balance across the organ as well as tissue biopsies to quantify the balance of organ mass storage. For humans such data already exists for skeletal muscle [51-53] and brain [54,55] However, for the human brain, biopsy data is normally not available in vivo, albeit they may be obtained in special cases [56]. In addition, similar data sets may be generated by the use of non-radioactive, stable isotope technique $[45,53,57]$. In animal studies it will be possible to obtain complete data sets for all major organ systems, using also radioactive tracer techniques, albeit multi-organ data from the same animal will be technically very demanding.

While it is mathematically straightforward to expand this modular approach to more detailed structures, like cell types within an organ, or indeed the organelles of the cell, the major challenge in this direction will be to collect the necessary data. In contrast to the methodology proposed here for whole organs, the experimental techniques for probing input-output relations at the cellular or subcellular level will be highly dependent on the system studied. Even if no data can be obtained, the individual submodules would of course still be subject to wholeorgan constraints. The modular nature of the approach would make it natural to adapt many of the modular techniques already in use in systems biology for constraining the individual submodules [12-17].

\subsection{Limitations}

One major assumption of the modelling framework as it is presented here is that the connecting compartments are biochemically inert. Biochemical processes do indeed occur in blood plasma, and some enzyme activities are present, but we expect that the overall metabolic activity is negligible compared to that of the organs. If this assumption proves wrong in special cases, we suggest that models of the unexplained metabolic activity can be described as a new organ model connected to the compartment in question.

While we have chosen to focus the description on well defined physiological states, a natural extension of the proposed strategy would be to collect metabolite concentration and flux data during transitions from one physiological state to another, like rest to exercise, fed to fasted or normal to diseased states. Experimentally, this would involve time series sampled at a suitable time resolution. This data can serve as additional input to the organ model adaptation step, for example by using a forcing approach to ensure a more realistic behaviour of the full model.

At this stage our framework does not include modelling of the blood circulation. However, during transitions between states, e.g. rest to exercise, there are major flow changes. Such changes could, however, be modelled based upon experimental monitoring of blood flow by ultrasound Doppler sonography [44].

\subsection{The Process of Generating Whole-Body Models}

The workflow associated with the construction of the full model, applying the formalism detailed above, is illustrated in Figure 3. As shown the assembly and formulation is associated with a number of work processes. We suggest some tools needed for these work processes in the methods section. In the supplementary material the use of the formalism is exemplified by steady state data sets for human metabolism in the fed and the fasted state, and the adaptation of existing silicon-cell organ models to these data sets is exemplified with an existing erythrocyte model $[9,10]$.

The formats necessary for the collaborative process are described in detail in Supplementary material. In short, whole-body model structures are represented in custom XML files with a hierarchical structure of physiological states, organs, connecting compartments and transported or stored metabolites. Organ models are represented in SBML [58] with additional identifiers that denote the name of the organ, and list the reactions that correspond to transport in and out of connecting compartments.

To make the proposed whole-body modelling approach operational, and add-on package to the SBtoolbox2 [59], that can perform the processes indicated by circles in Figure 3 would solve the problem. The construction of whole-body models is, however, entirely implementation specific, and the standardised file formats will allow alternative tools to be constructed.

\subsection{Example 1: A Simple Whole-Body Model Structure}

To illustrate the structures of the constraint and flow direction matrices introduced above, we introduce the simple model of the Cori cycle given in Figure 4. The model keeps track of extracellular glucose and lactate as well as glycogen storage, in that order. The connecting compartments are ordered as \{arterial plasma, venous plasma\}. The organs are ordered as: \{muscle, liver, $\mathrm{IO}$.

The exchange matrices for this system become:

$$
\mathbf{D}_{\text {muscle }}=\mathbf{D}_{\text {liver }}=\mathbf{D}_{\mathrm{IO}}=\left(\begin{array}{ll}
1 & 0 \\
0 & 1 \\
0 & 0
\end{array}\right) \text {. }
$$

The flux direction matrices become: 


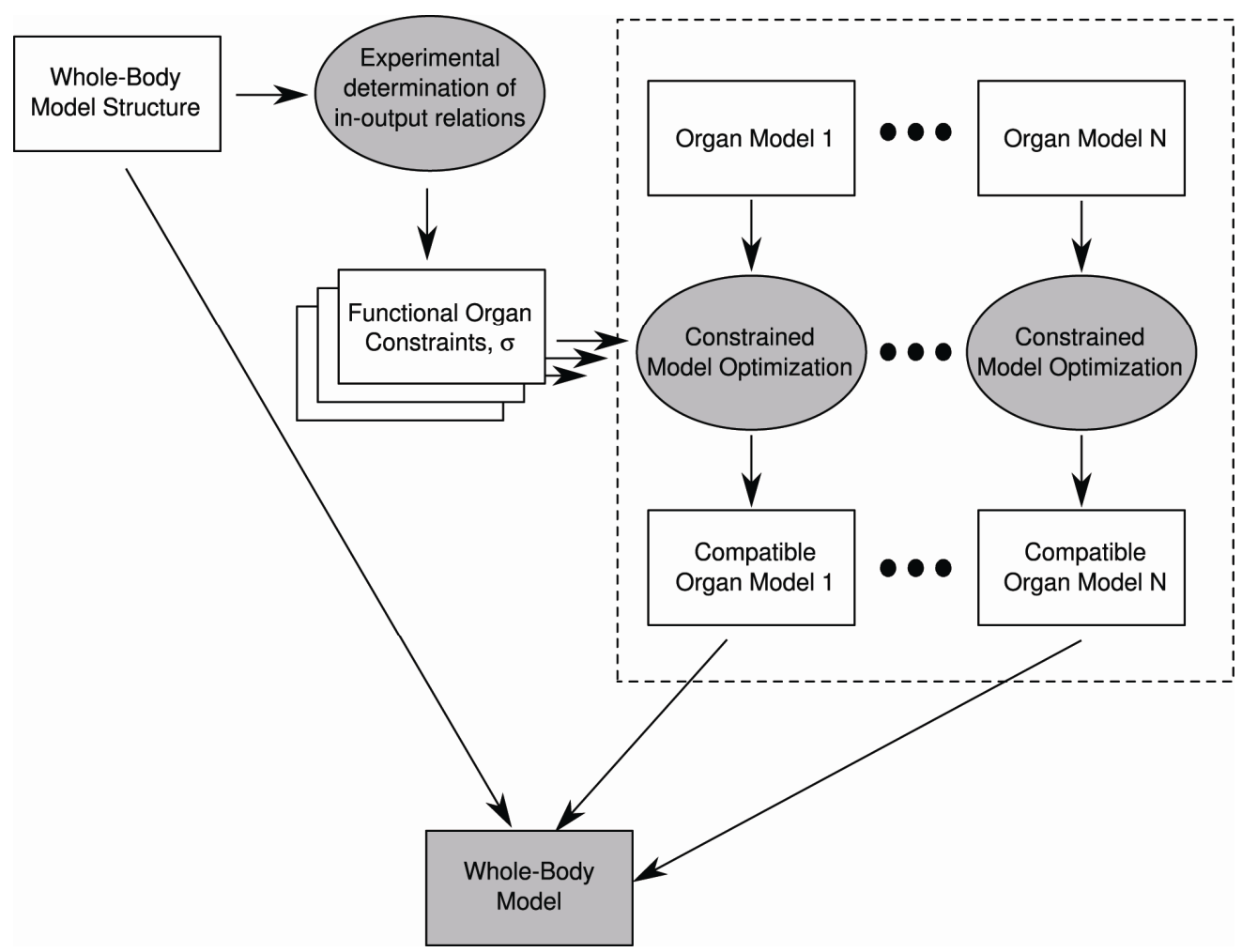

Figure 3. Workflow for the construction of whole-body models. Ellipses represent work processes, squares information or data structures. Greyed shapes indicate application or researcher specific processes/data structures; white represent data structures that requires a fixed format for collaboration.

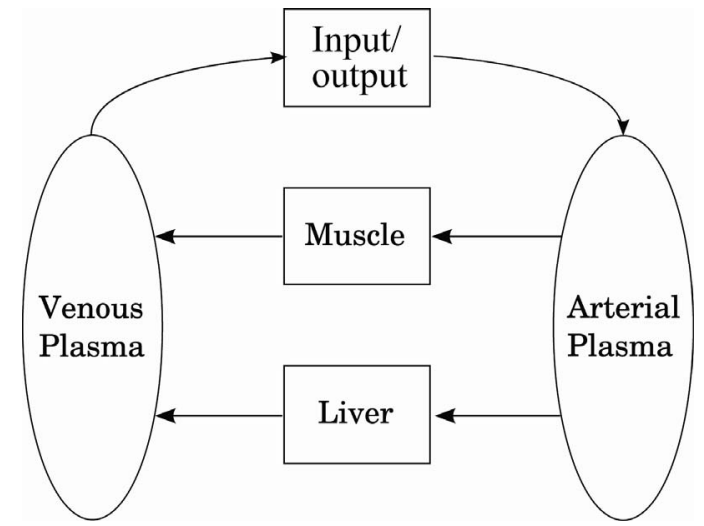

Figure 4. Simple Cori cycle whole-body model structure.

$$
\tilde{\mathbf{D}}_{\text {muscle }}=\tilde{\mathbf{D}}_{\text {liver }}=\left(\begin{array}{cc}
-1 & 0 \\
0 & 1 \\
0 & 0
\end{array}\right), \quad \tilde{\mathbf{D}}_{\mathrm{IO}}=\left(\begin{array}{cc}
1 & 0 \\
0 & -1 \\
0 & 0
\end{array}\right) \text {. }
$$

The amount matrix for the system in a given state could be:

$$
\mathbf{n}=\left(\begin{array}{cc}
n_{\mathrm{A}, \text { glucose }} & n_{\mathrm{V}, \text { glucose }} \\
n_{\mathrm{A}, \text { lactate }} & n_{\mathrm{V}, \text { lactate }} \\
0 & 0
\end{array}\right)
$$

where $\mathrm{A}$ and $\mathrm{V}$ denotes arterial and venous plasma, re- spectively.

The functional organ constraint matrix for an organ has the following structure:

$$
\mathbf{b}_{\text {liver }}^{\sigma}=\left(\begin{array}{ccc}
t_{\mathrm{A}, \text { glucose }} & t_{\mathrm{V}, \text { glucose }} & s_{\text {glucose }} \\
t_{\mathrm{A}, \text { lactate }} & t_{\mathrm{V}, \text { lactate }} & s_{\text {lactate }} \\
t_{\mathrm{A}, \text { glycogen }} & t_{\mathrm{V}, \text { glycogen }} & s_{\text {glycogen }}
\end{array}\right)
$$

where $t$ denotes the amount transported per time to or from a compartment, and $s$ storage per time in the organ. The matrix function $\mathbf{b}_{\text {liver }}$ has the same structure, only with functions instead of specific numbers.

\subsection{Example 2: Functional Organ Constraints and Adaptation of an Organ Model}

\subsubsection{Functional Organ Constraints}

An example of a more detailed whole-body model structure is shown in Figure 5. Tables 1 and $\mathbf{2}$ show estimates of the corresponding organ input-output relations in two physiological states, i.e. the tables provide functional organ constraints ( $\mathbf{b}_{i}^{\sigma}$ matrices) for construction of organ models that match the two physiological states. One of the states is the early post-absorptive state, where glycogen is being synthesized in liver and skeletal muscle, triglycerides are being stored in adipose tissue, and protein is being build up in skeletal muscle. The other 


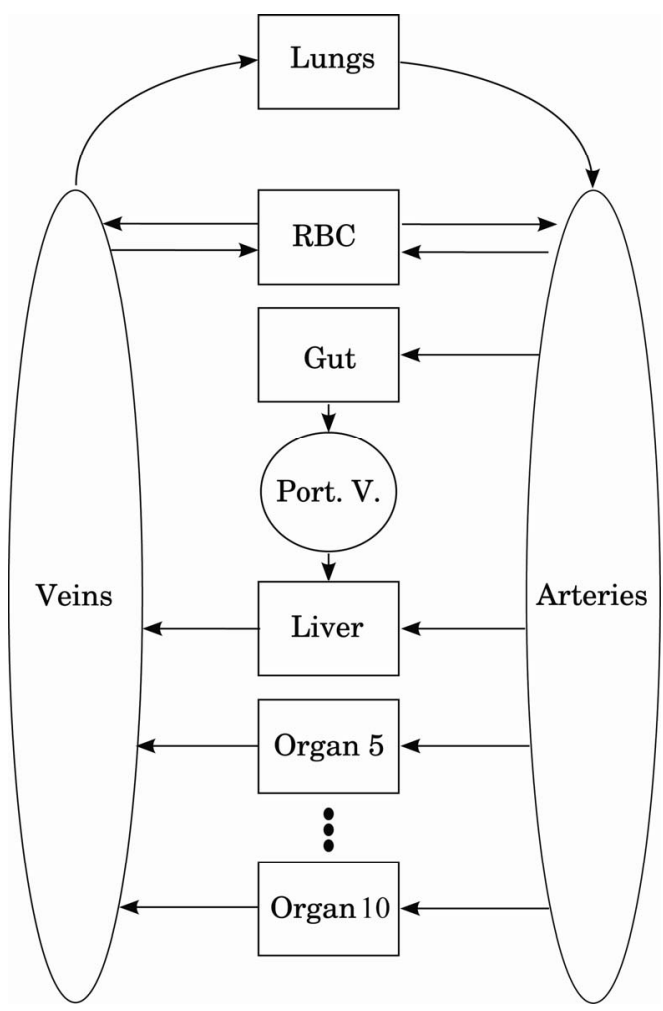

Figure 5. The whole-body model structure of Tables 1 and 2. Organs 5 - $10=$ muscle, fat, brain, heart, kidney, other $\}$. Port V. is the portal vein, and the $\mathrm{RBC}$ organ is the erythrocytes.

Table 1. Functional organ constraints for the early post-absorptive phase ( $\sigma=$ pap).

\begin{tabular}{|c|c|c|c|c|c|c|c|c|c|c|c|c|c|}
\hline & $\begin{array}{c}\Delta \mathbf{b}_{\text {liver }}^{\text {pap }} \\
(\mu \mathrm{mol} / \mathrm{min})\end{array}$ & $\begin{array}{c}\Delta \mathbf{b}_{\text {muscle }}^{\text {pap }} \\
(\mu \mathrm{mol} / \mathrm{min})\end{array}$ & $\begin{array}{c}\Delta \mathbf{b}_{\mathrm{fat}}^{\mathrm{pap}} \\
(\mu \mathrm{mol} / \mathrm{min})\end{array}$ & $\begin{array}{c}\Delta \mathbf{b}_{\text {brain }}^{\text {pap }} \\
(\mu \mathrm{mol} / \mathrm{min})\end{array}$ & $\begin{array}{c}\Delta \mathbf{b}_{\text {heart }}^{\text {pap }} \\
(\mu \mathrm{mol} / \mathrm{min})\end{array}$ & $\begin{array}{c}\Delta \mathbf{b}_{\text {kidney }}^{\text {pap }} \\
(\mu \mathrm{mol} / \mathrm{min})\end{array}$ & $\begin{array}{c}\Delta \mathbf{b}_{\mathrm{RBC}}^{\mathrm{pap}} \\
(\mu \mathrm{mol} / \mathrm{min})\end{array}$ & $\begin{array}{c}\Delta \mathbf{b}_{\mathrm{gut}}^{\mathrm{pap}} \\
(\mu \mathrm{mol} / \mathrm{min})\end{array}$ & $\begin{array}{c}\Delta \mathbf{b}_{\text {other }}^{\text {pap }} \\
(\mu \mathrm{mol} / \mathrm{min})\end{array}$ & $\begin{array}{c}\Delta \mathbf{b}_{\text {lungs }}^{\text {pap }} \\
(\mu \mathrm{mol} / \mathrm{min})\end{array}$ & $\begin{array}{c}\mathbf{c}_{A}^{\mathrm{pap}} \\
(\mathrm{mM})\end{array}$ & $\begin{array}{c}\mathbf{c}_{P V}^{\text {pap }} \\
(\mathrm{mM})\end{array}$ & $\begin{array}{c}\mathbf{c}_{V}^{\mathrm{pap}} \\
(\mathrm{mM})\end{array}$ \\
\hline glucose & -724 & -840 & -646 & -452 & -103 & -90 & -155 & 3140 & -129 & 0 & 5.7 & 9.3 & \\
\hline lactate & -116 & 0 & -194 & 0 & 0 & 0 & 310 & 0 & 0 & 0 & 0.9 & 0.9 & \\
\hline FA & 26 & -278 & 0 & 0 & -32 & -14 & 0 & 311 & -13 & 0 & 8 & 8.4 & \\
\hline $\mathrm{AA}$ & -827 & -1292 & 0 & 0 & 0 & 0 & 0 & 2119 & 0 & 0 & 1.6 & 4.3 & \\
\hline urea & 414 & 0 & 0 & 0 & 0 & -414 & 0 & 0 & 0 & 0 & 5 & 5 & \\
\hline KB & 0 & 0 & 0 & 0 & 0 & 0 & 0 & 0 & 0 & 0 & 0.1 & 0.1 & \\
\hline $\mathrm{O}_{2}$ & -2623 & -7224 & -246 & -2714 & -1460 & -912 & 0 & -1551 & -1111 & 17840 & 8.0 & 6.0 & 4.3 \\
\hline $\mathrm{CO}_{2}$ & 2416 & 5001 & 1512 & 2714 & 1202 & 799 & 0 & 1551 & 1008 & -16202 & 20 & 22 & 23 \\
\hline glycogen & 646 & 840 & 0 & 0 & 0 & 0 & 0 & 0 & 0 & 0 & & & \\
\hline TG & 0 & 0 & 52 & 0 & 0 & 0 & 0 & 0 & 0 & 0 & & & \\
\hline \multirow[t]{3}{*}{ protein } & 0 & 1292 & 0 & 0 & 0 & 0 & 0 & 0 & 0 & 0 & & & \\
\hline & $\begin{array}{c}J_{\text {liver }}^{\text {pap }} \\
(\mathrm{mL} / \mathrm{min})\end{array}$ & $\begin{array}{c}J_{\text {muscle }}^{\text {pap }} \\
(\mathrm{mL} / \mathrm{min})\end{array}$ & $\begin{array}{c}J_{\text {fat }}^{\text {pap }} \\
(\mathrm{mL} / \mathrm{min})\end{array}$ & $\begin{array}{c}J_{\text {brain }}^{\text {pap }} \\
(\mathrm{mL} / \mathrm{min})\end{array}$ & $\begin{array}{c}J_{\text {heart }}^{\text {pap }} \\
(\mathrm{mL} / \mathrm{min})\end{array}$ & $\begin{array}{c}J_{\text {kidney }}^{\text {pap }} \\
(\mathrm{mL} / \mathrm{min})\end{array}$ & $\begin{array}{c}J_{\mathrm{RBC}}^{\mathrm{pap}} \\
(\mathrm{mL} / \mathrm{min})\end{array}$ & $\begin{array}{c}J_{\text {gut }}^{\text {pap }} \\
(\mathrm{mL} / \mathrm{min})\end{array}$ & $\begin{array}{c}J_{\text {other }}^{\text {pap }} \\
(\mathrm{mL} / \mathrm{min})\end{array}$ & $\begin{array}{c}J_{\text {lungs }}^{\text {pap }} \\
(\mathrm{mL} / \mathrm{min})\end{array}$ & & & \\
\hline & $325+800$ & 1000 & 250 & 600 & 200 & 800 & - & 800 & 1025 & 5000 & & & \\
\hline
\end{tabular}

$J_{i}^{\sigma} \quad$ is the blood flow through organ $i[63], \Delta b_{i}^{\sigma}$ denotes the net rate of uptake of the corresponding organ, and $\mathrm{c}_{A}^{\sigma}$, $\mathrm{c}_{V}^{\sigma}$, and $\mathrm{c}_{P V}^{\sigma} \quad$ denote the concentrations in the arterial, venous, and portal vein connecting compartments, respectively. Concentrations, which are irrelevant for the functional organ constraints, are not included. AA is quantified as alanine, FA as $\mathrm{C} 18 \mathrm{H} 36 \mathrm{O} 2$, glycogen as glucose residues, $\mathrm{KB}$ as $\beta$-hydroxybutyrate, TG as $\mathrm{C} 57 \mathrm{H} 110 \mathrm{O} 6$, and protein as alanine residues. A total blood volume of $5 \mathrm{~L}$ is assumed, and the blood distribution is $20 \%$ arterial, $70 \%$ venous and $10 \%$ other [64]. Abbreviations: AA, amino acids; FA, fatty acids; KB, ketone bodies; RBC, red blood cells (erythrocytes); TG, triglycerides. 
Table 2. Functional organ constraints for 36 hours of starvation $(\sigma=$ stv). The cardiac output has been scaled to match the reduced energy turnover [65]. See Table 1 for additional details and explanations.

\begin{tabular}{|c|c|c|c|c|c|c|c|c|c|c|c|c|c|}
\hline & $\begin{array}{c}\Delta \mathbf{b}_{\text {liver }}^{\text {stv }} \\
(\mu \mathrm{mol} / \mathrm{min})\end{array}$ & $\begin{array}{c}\Delta \mathbf{b}_{\text {muscle }}^{\text {stv }} \\
(\mu \mathrm{mol} / \mathrm{min})\end{array}$ & $\begin{array}{c}\Delta \mathbf{b}_{\text {fat }}^{\text {stv }} \\
(\mu \mathrm{mol} / \mathrm{min})\end{array}$ & $\begin{array}{c}\Delta \mathbf{b}_{\text {brain }}^{\text {stv }} \\
(\mu \mathrm{mol} / \mathrm{min})\end{array}$ & $\begin{array}{c}\Delta \mathbf{b}_{\text {heart }}^{\text {stv }} \\
(\mu \mathrm{mol} / \mathrm{min})\end{array}$ & $\begin{array}{c}\Delta \mathbf{b}_{\text {kidney }}^{\text {stv }} \\
(\mu \mathrm{mol} / \mathrm{min})\end{array}$ & $\begin{array}{c}\Delta \mathbf{b}_{\mathrm{RBC}}^{\mathrm{stv}} \\
(\mu \mathrm{mol} / \mathrm{min})\end{array}$ & $\begin{array}{c}\Delta \mathbf{b}_{\text {gut }}^{\text {stv }} \\
(\mu \mathrm{mol} / \mathrm{min})\end{array}$ & $\begin{array}{c}\Delta \mathbf{b}_{\text {other }}^{\text {stv }} \\
(\mu \mathrm{mol} / \mathrm{min})\end{array}$ & $\begin{array}{c}\Delta \mathbf{b}_{\text {lungs }}^{\text {stv }} \\
(\mu \mathrm{mol} / \mathrm{min})\end{array}$ & $\begin{array}{c}\mathbf{c}_{A}^{\mathrm{st}} \\
(\mathrm{mM})\end{array}$ & $\begin{array}{c}\mathbf{c}_{P V}^{\mathrm{stv}} \\
(\mathrm{mM})\end{array}$ & $\begin{array}{c}\mathbf{c}_{V}^{\mathrm{sv}} \\
(\mathrm{mM})\end{array}$ \\
\hline glucose & 613 & -44 & 0 & -298 & -18 & -61 & -105 & 0 & -88 & 0 & 4.6 & 4.6 & \\
\hline lactate & -210 & 0 & 0 & 0 & 0 & 0 & 210 & 0 & 0 & 0 & 0.9 & 0.9 & \\
\hline FA & -57 & -118 & 232 & 0 & -13 & 0 & 0 & 0 & -44 & 0 & 10 & 10 & \\
\hline AA & -1016 & 1016 & 0 & 0 & 0 & 0 & 0 & 0 & 0 & 0 & 2.1 & 2.1 & \\
\hline urea & 508 & 0 & 0 & 0 & 0 & -508 & 0 & 0 & 0 & 0 & 10 & 10 & \\
\hline $\mathrm{KB}$ & 22 & 0 & 0 & -9 & -13 & 0 & 0 & 0 & 0 & 0 & 2 & 2 & \\
\hline $\mathrm{O}_{2}$ & -1381 & -3336 & -271 & -1826 & -506 & -368 & 0 & 0 & -1664 & 9352 & 8 & 8 & 4.3 \\
\hline $\mathrm{CO}_{2}$ & 429 & 2391 & 232 & 1821 & 394 & 368 & 0 & 0 & 1314 & -6949 & 20 & 20 & 23 \\
\hline glycogen & 0 & 0 & 0 & 0 & 0 & 0 & 0 & 0 & 0 & 0 & & & \\
\hline TG & 0 & 0 & -77 & 0 & 0 & 0 & 0 & 0 & 0 & 0 & & & \\
\hline \multirow[t]{3}{*}{ protein } & 0 & -1016 & 0 & 0 & 0 & 0 & 0 & 0 & 0 & 0 & & & \\
\hline & $\begin{array}{c}J_{\text {liver }}^{\text {stv }} \\
(\mathrm{mL} / \mathrm{min})\end{array}$ & $\begin{array}{c}J_{\text {muscle }}^{\text {stv }} \\
(\mathrm{mL} / \mathrm{min})\end{array}$ & $\begin{array}{c}J_{\text {fat }}^{\text {stv }} \\
(\mathrm{mL} / \mathrm{min})\end{array}$ & $\begin{array}{c}J_{\text {brain }}^{\text {stv }} \\
(\mathrm{mL} / \mathrm{min})\end{array}$ & $\begin{array}{c}J_{\text {heart }}^{\text {stv }} \\
(\mathrm{mL} / \mathrm{min})\end{array}$ & $\begin{array}{c}J_{\text {kidney }}^{\text {stv }} \\
(\mathrm{mL} / \mathrm{min})\end{array}$ & $\begin{array}{c}J_{\mathrm{RBC}}^{\mathrm{stv}} \\
(\mathrm{mL} / \mathrm{min})\end{array}$ & $\begin{array}{c}J_{\text {gut }}^{\mathrm{stv}} \\
(\mathrm{mL} / \mathrm{min})\end{array}$ & $\begin{array}{c}J_{\text {other }}^{\text {stv }} \\
(\mathrm{mL} / \mathrm{min})\end{array}$ & $\begin{array}{c}J_{\text {lungs }}^{\text {stv }} \\
(\mathrm{mL} / \mathrm{min})\end{array}$ & & & \\
\hline & $163+400$ & 425 & 125 & 300 & 100 & 475 & - & 400 & 512 & 2500 & & & \\
\hline
\end{tabular}

state is the $36 \mathrm{~h}$ starved state where glycogen has been used up, and the organism is living off its own energy reserves, including breakdown of triglycerides for energy production and the use of muscle protein as substrate for the necessary hepatic gluconeogenesis, fueling brain, erythrocytes and other tissues needing glucose.

The estimates are constructed by considering the normal physiological functions of the organs in these two states [60-62], while also imposing a number of level 0 constraints. The major constraints are energy consumptions of $3000 \mathrm{kcal} / 24 \mathrm{~h}$ in the post-absorptive state and $1500 \mathrm{kcal} / 24 \mathrm{~h}$ in the starved state (this applies for a normal, young human) and the corresponding $\mathrm{O}_{2}$ and $\mathrm{CO}_{2}$ exchange rates in the lungs. We also impose mass balance and a whole-body steady-state criterium, Equation 2 in the main text with $D_{t} \mathbf{n}^{\sigma}=\mathbf{0}$. For simplicity, all protein is represented as poly-alanine, all amino acids as alanine, all carbohydrate as glucose and glycogen, all fatty acids as stearic acid and all triglyceride as glycerol-tri-stearyl. The energy consumption of the biosynthesis reactions included in the tables are not accounted for, but the overall oxidation of all the substrates involved, including the storage molecules, is accounted for by standard mass equations of oxidation, e.g. $\mathrm{CH}_{3}\left(\mathrm{CH}_{2}\right)_{16} \mathrm{COOH}+26 \mathrm{O}_{2}$ $\rightarrow 18 \mathrm{CO}_{2}+18 \mathrm{H}_{2} \mathrm{O}$ for the oxidation of stearic acid and $28 \mathrm{C}_{6} \mathrm{H}_{12} \mathrm{O}_{6}+5 \mathrm{O}_{2} \rightarrow 2 \mathrm{C}_{57} \mathrm{H}_{110} \mathrm{O}_{6}+54 \mathrm{CO}_{2}+58 \mathrm{H}_{2} \mathrm{O}$ for the synthesis of glycerol-tri-stearyl from glucose.

Functional organ constraints are given by $\mathbf{b}_{i}^{\sigma}$ matrices; these are presented in a condensed form in Table $\mathbf{1}$ and Table 2: For all organs except the erythrocytes $(\mathrm{RBC}), \mathbf{b}_{i}^{\sigma}$ is defined by the specific, constant blood flow through organ $i, J_{i}^{\sigma}$, and by its net metabolite up- take rates $\Delta \mathbf{b}_{i}^{\sigma}$. For the $\mathrm{RBC}$, there is no blood flow through the organ, and $\Delta \mathbf{b}_{\mathrm{RBC}}^{\sigma}$ is the net metabolite uptake rate. The $\mathbf{D}_{j}$ and $\tilde{\mathbf{D}}_{i}$ matrices are given implicitly by Figure 5.

\subsubsection{Adaptation of an Organ Model to Functional Organ Constraints}

We have applied the flux matching method and the model adjustment procedure to adjust the erythrocyte model described by Mulquiney and Kuchel [9] to the functional organ constraints described in Table 1. The erythrocyte model includes all major aspects of the erythrocyte's metabolism: the pentose phosphate pathway (PPP), glycolysis and the 2,3-bisphosphoglycerate shunt (2,3-BGP shunt). The reaction network consists of 59 net reactions and 63 metabolites and other substances. After fluxmatching, the model is left with four active net extreme currents. One of these is glycolysis, another is glycolysis where the phosphoglycerate kinase reaction is bypassed by the 2,3-BPG shunt. In addition, two net extreme currents related to the 2,3-BPG synthase/phosphatase complex are active, albeit with very low net fluxes. Solution of the quadratic programming problem (cf. Matching the fluxes of an organ model to a specific physiological state above) yields the optimal distribution of flux between these four extreme currents, and dictates that all other parts of the reaction network must have zero net flux. Biochemically, this corresponds to closing down the PPP because no $\mathrm{CO}_{2}$ production and no pyruvate consumption is allowed by the functional organ constraint $\mathbf{b}_{\mathrm{RBC}}^{\sigma}$. This results in a $6 \%$ relative decrease of the hexokinase flux, a relative flux increase of $2 \%-4 \%$ from phosphoglucoi- 
somerase to aldolase, and in less than $1 \%$ relative flux decrease in the lower part of glycolysis. The 2,3-BPG shunt has almost unaltered relative flux, and the relative increase of the ATPase flux is $1 \%$. To fix the model at this optimal steady-state flux, all $V_{\max }$ values are changed proportionally.

\section{Acknowledgements}

This work was supported by the European Union through the Network of Excellence BioSim, Contract No. LSHBCT-2004-005137, The Danish Strategic Research Council, No. 2101-05-0030 and by the ESF FYNCDYN Programme.

\section{REFERENCES}

[1] R. Gebhardt, "Heterogeneous Intrahepatic Distribution of Glutamine Synthetase," Acta Histochemica, Supplement, Vol. 40, 1990, pp. 23-28.

[2] C. Cori, "Mammalian Carbohydrate Metabolism," Physological Reviews, Vol. 11, No. 2, 1931, pp. 143-275.

[3] N. Secher and B. Quistorff, "Brain Glucose and Lactate Uptake during Exhaustive Exercise," Journal of Physiology, Vol. 568, 2005, p. 3. doi:10.1113/jphysiol.2005.095786

[4] L. Sokoloff, "Metabolism of Ketone Bodies by the Brain," Annual Review of Medicine, Vol. 24, No. 1, 1973, pp. 271-280. doi:10.1146/annurev.me.24.020173.001415

[5] S. Hasselbalch, P. Madsen, L. Hageman, K. Olsen, N. Justesen, S. Holm, et al., "Changes in Cerebral Blood Flow and Carbohydrate Metabolism during Acute Hyperketonemia," American Journal of Physiology, Vol. 270, No. 5, 1996, pp. 746-751.

[6] S. Kahn, R. Hull and K. Utzschneider, "Mechanisms Linking Obesity to Insulin Resistance and Type 2 Diabetes," Nature, Vol. 444, 2006, pp. 840-846. doi:10.1038/nature 05482

[7] E. Rosen and B. Spiegelman, "Adipocytes as Regulators of Energy Balance and Glucose Homeostasis," Nature, Vol. 444, 2006, pp. 847-853. doi:10.1038/nature05483

[8] C. Wang, C. Wang and Y. Wei, "Mitochondrial Dysfunction in Insulin Insensitivity: Implication of Mitochondrial Role in Type 2 Diabetes." Annals of the New York Academy of Sciences, Vol. 1201, 2010, pp. 157-65. doi:10.1111/j.1749-6632.2010.05625.x

[9] P. Mulquiney and P. Kuchel, "Model of 2,3-Bisphosphoglycerate Metabolism in the Human Erythrocyte Based on Detailed Enzyme Kinetic Equations: Equations and Parameter Refinement," Biochemical Journal, Vol. 342, 1999, pp. 567-580. doi:10.1042/0264-6021:3420567

[10] B. Hald, M. Madsen, S. Danø, B. Quistorff and P. Sørensen, "Quantitative Evaluation of Respiration Induced Metabolic Oscillations in Erythrocytes," Biophysical Chemistry, Vol. 141, No. 1, 2009, pp. 41-8. doi:10.1016/j.bpc.2008.12.008

[11] J. Tyson and B. Novak, "Regulation of the Eukaryotic
Cell Cycle: Molecular Antagonism, Hysteresis, and Irreversible Transitions," Journal of Theoretical Biology, Vol. 210, 2001, pp. 249-263.

[12] R. Hafner, G. Brown and M. Brand, "Analysis of the Control of Respiration Rate, Phosphorylation Rate, Proton Leak Rate and Protonmotive Force in Isolated Mitochondria Using the 'Top-Down' Approach of Metabolic Control Theory," FEBS Journal, Vol. 188, No. 2, 1990, pp. 313-319.

[13] J. Hofmeyr and A. Cornish-Bowden, "Regulating the Cellular Economy of Supply and Demand," FEBS Letters, Vol. 476, No. 1, 2000, pp. 47-51. doi:10.1016/S0014-5793(00)01668-9

[14] J. Ciapaite, G. Van Eikenhorst, S. Bakker, M. Diamant, R. Heine, M. Wagner, et al., "Modular Kinetic Analysis of the Adenine Nucleotide Translocator-Mediated Effects of Palmitoyl-CoA on the Oxidative Phosphorylation in Isolated Rat Liver Mitochondria," Diabetes, Vol. 54, No. 4, 2005, p. 944. doi:10.2337/diabetes.54.4.944

[15] D. Kahn and H. Westerhoff, "Control Theory of Regulatory Cascades," Journal of Theoretical Biology, Vol. 153, No. 2, 1991, pp. 255-285. doi:10.1016/S0022-5193(05)80426-6

[16] M. Brand, “Top Down Metabolic Control Analysis," Journal of Theoretical Biology, Vol. 182, No. 3, 1996, pp. 351-360. doi:10.1006/jtbi.1996.0174

[17] S. Schuster, D. Kahn and H. Westerhoff, "Modular Analysis of the Control of Complex Metabolic Pathways," Biophysical Chemistry, Vol. 48, No. 1, 1993, pp. 1-17. doi:10.1016/0301-4622(93)80037-J

[18] C. Csajka and D. Verotta, "Pharmacokinetic-Pharmacodynamic Modelling: History and Perspectives," Journal of Pharmacokinet and Pharmacodyn, Vol. 33, No. 3, 2006, pp. 227-279. doi:10.1007/s10928-005-9002-0

[19] I. Nestorov, "Whole Body Pharmacokinetic Models," Clinical Pharmacokinetics, Vol. 42, No. 10, 2003, pp. 883908. doi:10.2165/00003088-200342100-00002

[20] A. Edginton, F. Theil, W. Schmitt and S. Willmann, "Whole Body Physiologically-Based Pharmacokinetic Models: Their Use in Clinical Drug Development," Expert Opinion on Drug Metabolism and Toxicology, Vol. 4, No. 9, 2008, pp. 1143-52. doi: $10.1517 / 17425255.4 .9 .1143$

[21] A. Kansal, "Modeling Approaches to Type 2 Diabetes," Diabetes Technology \& Therapeutics, Vol. 6, No. 1, 2004, pp. 39-47. doi:10.1089/152091504322783396

[22] H. Kitano, K. Oda, T. Kimura, Y. Matsuoka, M. Csete, J. Doyle, et al., "Metabolic Syndrome and Robustness Tradeoffs," Diabetes, Vol. 53, No. 3, 2004, pp. 6-15. doi:10.2337/diabetes.53.suppl 3.S6

[23] M. Hjelm and J. Seakins, "Modeling Amino Acid Metabolism," Amino Acids, Vol. 3, No. 1, 1992, pp. 1-23. doi:10.1007/BF00806006

[24] G. Cedersund and P. Strålfors, "Putting the Pieces Together in Diabetes Research: Towards a Hierarchical Model of Whole-Body Glucose Homeostasis," European Journal of Pharmaceutical Sciences, Vol. 36, No. 31, 2009, pp. 91-104. 
[25] R. Bergman, L. Philips and C. Cobelli, "Physiologic Evaluation of Factors Controlling Glucose Tolerance in Man," Journal of Clinical Investigation, Vol. 68, No. 6, 1981, pp.1456-1467. doi:10.1172/JCI110398

[26] R. Basu, B. Camillo, G. Toffolo, A. Basu, P. Shah, A. Vella, et al., "Use of a Novel Triple-Tracer Approach to Assess Postprandial Glucose Metabolism," American Journal of Physiology-Endocrinology and Metabolism, Vol. 284, No. 1, 2003, pp. 55-69.

[27] C. Man, R. Rizza and C. Cobelli, "Meal Simulation Model of the Glucose-Insulin System," IEEE Transactions on Biomedical Engineering, Vol. 54, No. 10, 2007, pp. 1740-1749. doi:10.1109/TBME.2007.893506

[28] J. Kim, G. Saidel and M. Cabrera, "Multi-Scale Computational Model of Fuel Homeostasis during Exercise: Effect of Hormonal Control," Annals of Biomedical Engineering, Vol. 35, No. 1, 2007, pp. 69-90. doi:10.1007/s10439-006-9201-X

[29] D. Noble, "Modeling the Heart-From Genes to Cells to the Whole Organ," Science, Vol. 295, No. 5560, 2002, pp. 1678-1682. doi:10.1126/science.1069881

[30] S. Yeo, J. Kim, S. Lee, F. Park, W. Park, J. Kim, et al., "A Modular Object-Oriented Framework for Hierarchical Multi-Resolution Robot Simulation," Robotica, Vol. 22, No. 2, 2004, pp. 141-154. doi:10.1017/S0263574703005435

[31] C. Barwell and B. Hess, "Application of Kinetics of Yeast Pyruvate Kinase in Vitro to Calculation of Glycolytic Flux in the Anaerobic Yeast Cell," Hoppe-Seyler's Zeitschrift für Physiologische Chemie, Vol. 353, No. 2, 1972, pp. 1178-1184. doi:10.1515/bchm2.1972.353.2.1178

[32] B. Wright and P. Kelly, "Kinetic Models of Metabolism in Intact Cells, Tissues, and Organisms," Current Topics in Cellular Regulation, Vol. 19, 1981, pp. 103-158.

[33] B. Teusink, J. Passarge, C. A. Reijenga, E. Esgalhado, C. C. van der Weijden, M. Schepper, et al., "Can Yeast Glycolysis be Understood in Terms of in Vitro Kinetics of the Constituent Enzymes? Testing Biochemistry," European Journal of Biochemistry, Vol. 267, No. 17, 2000, pp. 5313-5329.

[34] I. Famili, R. Mahadevan and B. Palsson, "k-Cone Analysis: Determining All Candidate Values for Kinetic Parameters on a Network Scale," Biophysical Journal, Vol. 88 , No. 3, 2005, pp. 1616-1625. doi:10.1529/biophysj.104.050385

[35] P. A. Srere, "Macromolecular Interactions: Tracing the Roots," Trends in Biochemical Sciences, Vol. 25, No. 3, 2000, pp. 150-153. doi:10.1016/S0968-0004(00)01550-4

[36] J. Ovadi and V. Saks, "On the Origin of Intracellular Compartmentation and Organized Metabolic Systems," Molecular and Cellular Biochemistry, Vol. 256-257, No. 1-2, 2004, pp. 5-12.

[37] S. Schnell and T. Turner, "Reaction Kinetics in Intracellular Environments with Macromolecular Crowding: Simulations and Rate Laws," Progress in Biophysics and Molecular Biology, Vol. 85, No. 2-3, 2004, pp. 235-260.

[38] G. Reichel, "Waste-Water-A Library for Modelling and
Simulation of Wastewater Treatment Plants in Modelica," Proceeding of the 3rd International Modelica Conference, Lindköping, 2003, pp. 171-176.

[39] P. Fritzson, "Principles of Object-Oriented Modeling and Simulation with Modelica 2.1," Wiley-IEEE Press, New York, 2004. doi:10.1109/9780470545669

[40] A. Fick, "Uber die Messung des Blutquantums in den Herzventrikeln," Seitung der Physikalisches und Medicinisches Gesellschaft zu Würzburg, Vol. 2, 1870, pp. 290-291.

[41] P. Rasmussen, P. Plomgaard, R. Krogh-Madsen, Y. Kim, N. Secher and B. Quistorff, "MCA Vmean and the Arterial Lactate-to-Pyruvate Ratio Correlate during Rhythmic Handgrip," Journal of Applied Physiology, Vol. 101, No. 5, 2006, pp. 1406-1411. doi:10.1152/japplphysiol.00423.2006

[42] P. Rasmussen, N. Nyberg, J. Jaroszewski, R. KroghMadsen, N. Secher and B. Quistorff, "Brain Nonoxidative Carbohydrate Consumption Is Not Explained by Export of an Unknown Carbon Source: Evaluation of the Arterial and Jugular Venous Metabolome," Journal of Cerebral Blood Flow \& Metabolism, Vol. 30, No. 6, 2010, pp. 1240-1246. doi:10.1038/jcbfm.2010.25

[43] B. Quistorff, N. Secher and J. Van Lieshout, "Lactate Fuels the Human Brain during Exercise," FASEB Journal, Vol. 22, No. 10, 2008, pp. 3443-3449. doi:10.1096/fj.08-106104

[44] P. Rasmussen, C. Madsen, H. Nielsen, M. Zaar, A. Gjedde, N. Secher, et al., "Coupling between the Blood Lactate-to-Pytuvate Ratio and MCA Vmean at the Onset of Exercise in Humans," Journal of Applied Physiology, Vol. 107, No. 6, 2009, pp. 1799-805. doi:10.1152/japplphysiol.00468.2009

[45] G. Van Hall, M. Strømstad, P. Rasmussen, O. Jans, M. Zaar, C. Gam, et al., "Blood Lactate Is an Important Energy Source for the Human Brain," Journal of Cerebral Blood Flow \& Metabolism, Vol. 29, No. 6, 2009, pp. 1121-9. doi:10.1038/jcbfm.2009.35

[46] F. Hynne, S. Danø and P. G. Sorensen, "Full-Scale Model of Glycolysis in Saccharomyces Cerevisiae," Biophysical Chemistry, Vol. 94, No. 1-2, 2001, pp. 121-163. doi:10.1016/S0301-4622(01)00229-0

[47] B. Clarke, "Stability of Complex Reaction Networks," Advances in Chemical Physics, Vol. 43, 1980, pp. 1-215. doi:10.1002/9780470142622.ch1

[48] M. Kozlov, S. Tarasov and L. Khachiyan, "Polynomial Solvability of Convex Quadratic Programming," Soviet Mathematics Doklady, Vol. 20, 1979, pp. 1108-1111.

[49] H. Sherali and C. H. Tuncbilek, "A Global Optimization Algorithm for Polynomial Programming Problems Using a Reformulation-Linearization Technique," Journal of Global Optimization, Vol. 2, No. 1, 1992, pp. 101-112. doi:10.1007/BF00121304

[50] Y.-J. Chang and B. W. Wah, "Polynomial Programming Using Groebner Bases," Computer Software and Applications Conference, Taiwan, 9-11 November 1994, pp. 236241.

[51] H. Nielsen, M. Febbraio, P. Ott, P. Krustrup and N. 
Secher, "Hepatic Lactate Uptake versus Leg Lactate Output during Exercise in Humans," Journal of Applied Physiology, Vol. 103, No. 4, 2007, pp. 1227-33. doi:10.1152/japplphysiol.00027.2007

[52] H. Nielsen, N. Secher, O. Clemmesen and P. Ott, "Maintained Cerebral and Skeletal Muscle Oxygenation during Maximal Exercise in Patients with Liver Cirrhosis," Journal of Hepatology, Vol. 43, No. 2, 2005, pp. 266-271. doi:10.1016/i.jhep.2005.02.039

[53] U. Sauer, "Metabolic Networks in Motion: 13C-Based Flux Analysis," Molecular Systems Biology, Vol. 2, No. 14, 2006, p. 62. doi:10.1038/msb4100109

[54] L. Nybo, M. Dalsgaard, A. Steensberg, K. Moller and N. Secher, "Cerebral Ammonia Uptake and Accumulation during Prolonged Exercise in Humans," Journal of Physiology, Vol. 563, Pt. 1, 2005, pp. 285-290. doi:10.1113/jphysiol.2004.075838

[55] M. Dalsgaard, B. Quistorff, E. Danielsen, C. Selmer, T. Vogelsang and N. Secher, "A Reduced Cerebral Metabolic Ratio in Exercise Reflects Metabolism and Not Accumulation of Lactate within the Human Brain," Journal of Physiology, Vol. 554, Pt. 2, 2004, pp. 571-578. doi:10.1113/jphysiol.2003.055053

[56] M. Dalsgaard, F. Madsen, N. Secher, H. Laursen and B. Quistorff, "High Glycogen Levels in the Hippocampus of Patients with Epilepsy," Journal of Cerebral Blood Flow \& Metabolism, Vol. 27, 2007, pp. 1137-41. doi:10.1038/sj.jcbfm.9600426

[57] R. Shulman and D. Rothman, "13C NMR of Intermediary
Metabolism: Implications for Systemic Physiology," Annual Review of Physiology, Vol. 63, 2001, pp. 15-48. doi:10.1146/annurev.physiol.63.1.15

[58] M. Hucka, A. Finney, H. M. Sauro, H. Bolouri, J. C. Doyle, H. Kitano, et al., "The Systems Biology Markup Language (SBML): A Medium for Representation and Exchange of Biochemical Network Models," Bioinformatics, Vol. 19, No. 4, 2003, pp. 524-531. doi:10.1093/bioinformatics/btg015

[59] H. Schmidt and M. Jirstrand, "Systems Biology Toolbox for MATLAB: A Computational Platform for Research in Systems Biology," Bioinformatics, Vol. 22, No. 4, 2006, pp. 514-515. doi:10.1093/bioinformatics/bti799

[60] K. Frayn, "Metabolic Regulation: A Human Perspective," Portland Press, Portland, 2001.

[61] T. Devlin, “Textbook of Biochemistry," Wiley-Liss Incorporated, Wilmington, 1997.

[62] E. Newsholme and A. Leech, "Biochemistry for the Medical Sciences," John Wiley \& Sons, New York, 1984.

[63] L. Williams and R. Leggett, "Reference Values for Resting Blood Flow to Organs of Man," Clinical Physics and Physiological Measurement, Vol. 10, No. 3, 1989, pp. 187-217. doi:10.1088/0143-0815/10/3/001

[64] W. Boron and E. Boulpaep, "Medical Physiology," Saunders Press, Philadelphia, 2003.

[65] A. C. Guyton, C. E. Jones and T. G. Coleman, "Circulatory Physiology: Cardiac Output and Its Regulation," 2nd Edition, W. B. Saunders Company, Philadelphia, 1973.

\section{Supplementary Material: Data representation \\ Representation of Whole-Body Models and Their Components}

\section{Representation of Entities by Identifiers}

Unambiguous definitions of all entities are insured by the use of unique identifiers in the model descriptions. A unique identifier is a name (an NC name data type in XML Schema) and a Uniform Resource Identifier (URI). The URI serves as a name space for the identifier, pointing to the source of the original definition of the name. For large projects a list of identifiers should be maintained at the project website - this database will include additional information about the species like the CAS number or number of carbon, nitrogen, and oxygen atoms if available. The identifiers facilitate collaboration by making it possible for individual research groups to use their own local names for entities. The inclusion of a URI serves to allow different groups of researchers to define their own sets of identifiers without having to worry about potential naming collisions. This scheme obviates the need for a central authority to issue unique identifiers.

The identifiers make it possible for individual research groups to use their own local names for entities, while still facilitating collaboration by including unique identifiers. The inclusion of a URI serves to allow different groups of researchers to avoid the headache of avoiding naming collision. In this scheme there is no need for a central authority for assigning unique identifiers.

Entities represented by identifiers are chemical species, organs, connecting compartments, physiological states and organ connections (identifying specific in- and out-flows from the organs). These identifiers are referenced in both the organ and whole-body files, providing a means to connect the individual organs.

Identifiers can be left out if the modelling framework is used for smaller projects. In this case, the entity is referenced by using the local name in the XML file. The author is then advised to include contact information and a description of 
the entity in the XML document.

\section{The Whole-Body Model Structure}

The model structure file format has several types: the WBM_MODEL_INSTANCE, WBM_MODEL_CONSTRAINTS and WBM_MODEL_STRUCTURE, each with different restrictions on content.

The top of the document specifies the document type, then follows a set of fields: Model information, list of physiological states, list of compartments, list of species and, finally, a list of organs.

$<$ ?xml version="1.0"?>

<wbms type="WBM_MODEL_INSTANCE" xmlns=" http://HuMMproject.org/wbm/v0/structure">

$</$ wbms $>$

\section{Model Information}

Contains an author name and model notes. Author information is required in all file sub-types. Notes are always optional.

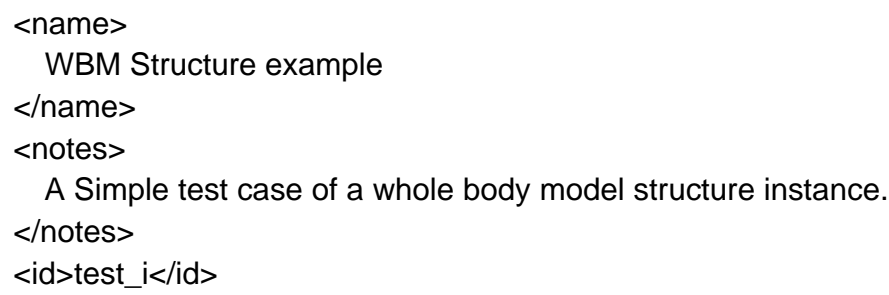

\section{List of Physiological States}

The list of physiological states references a number of physiological states, which the organ models are required to fulfill. Each physiological state has a local name and a list of IDs, containing the URI of the state definition.

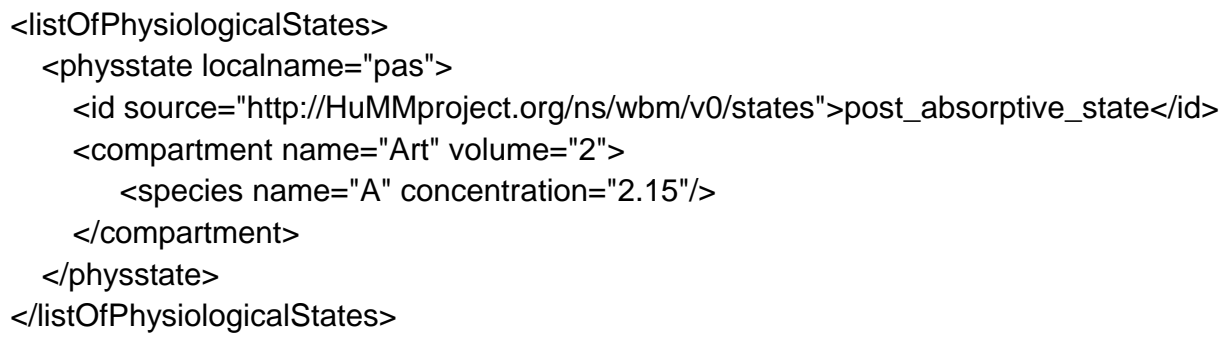

\section{List of Compartments}

List of Compartments contains a list of connecting compartments. Each compartment has an optional attribute specifying the initial volume, and a list of IDs. Finally, if physiological states have been defined, a volume must be specified for each state (referencing the local name of the state).

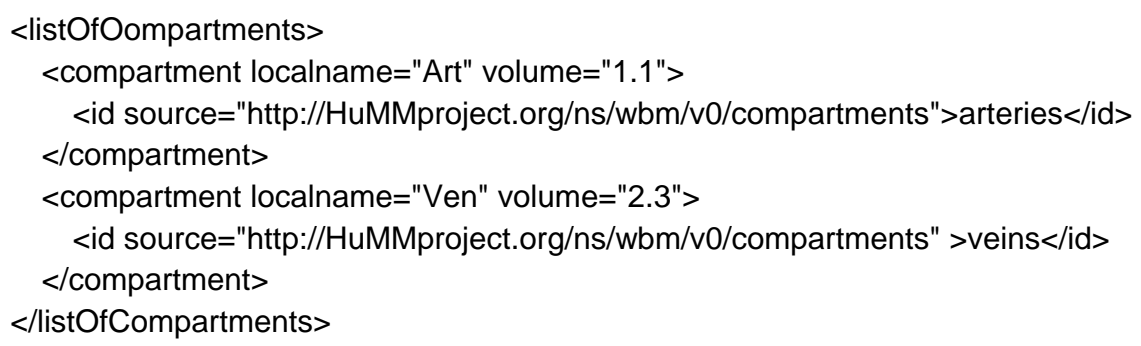

\section{List of Species}

The list of species contains a list of the species present in the connecting compartments. Each of these species contain a 
list of IDs as well as the initial concentration in each connecting compartment. Finally, each species contains a list of concentrations in each compartment for each defined physiological state. Initial conditions are required only for the model instance, and the physiological state concentrations are required only for the model constraints.

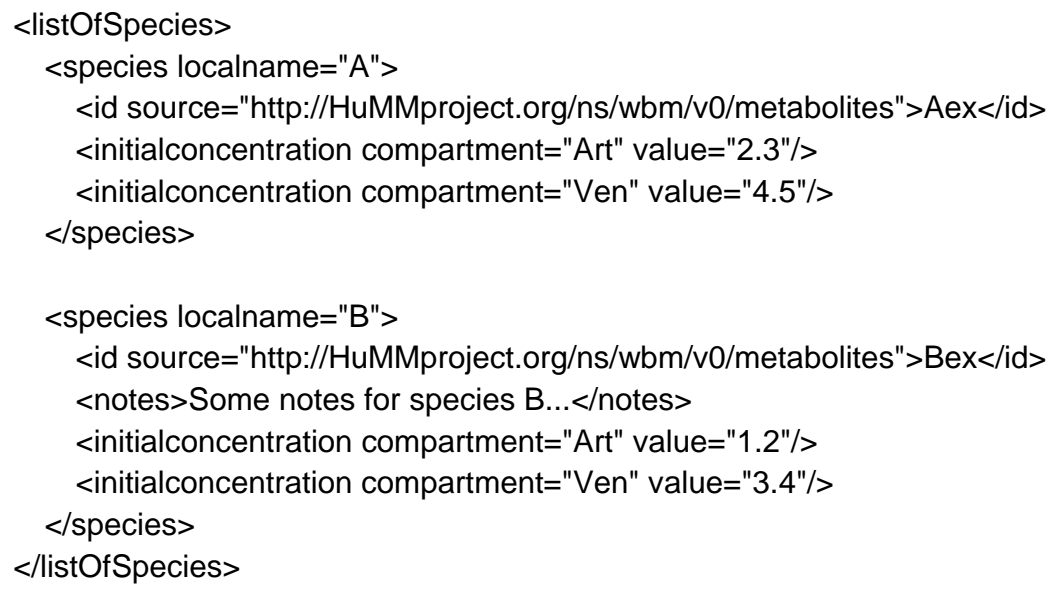

\section{List of Organs}

The list of organs introduces the organs of the model and their connections to the connecting compartments. Each organ contains a list of IDs, and a list of connections. The connection specifies the name of the flow direction, and a previously defined connecting compartment. The connection also contains an ID, specifying the type of connection (used internally in the organ model). If physiological states have been defined, the model contains a list of input-output relations for each state.

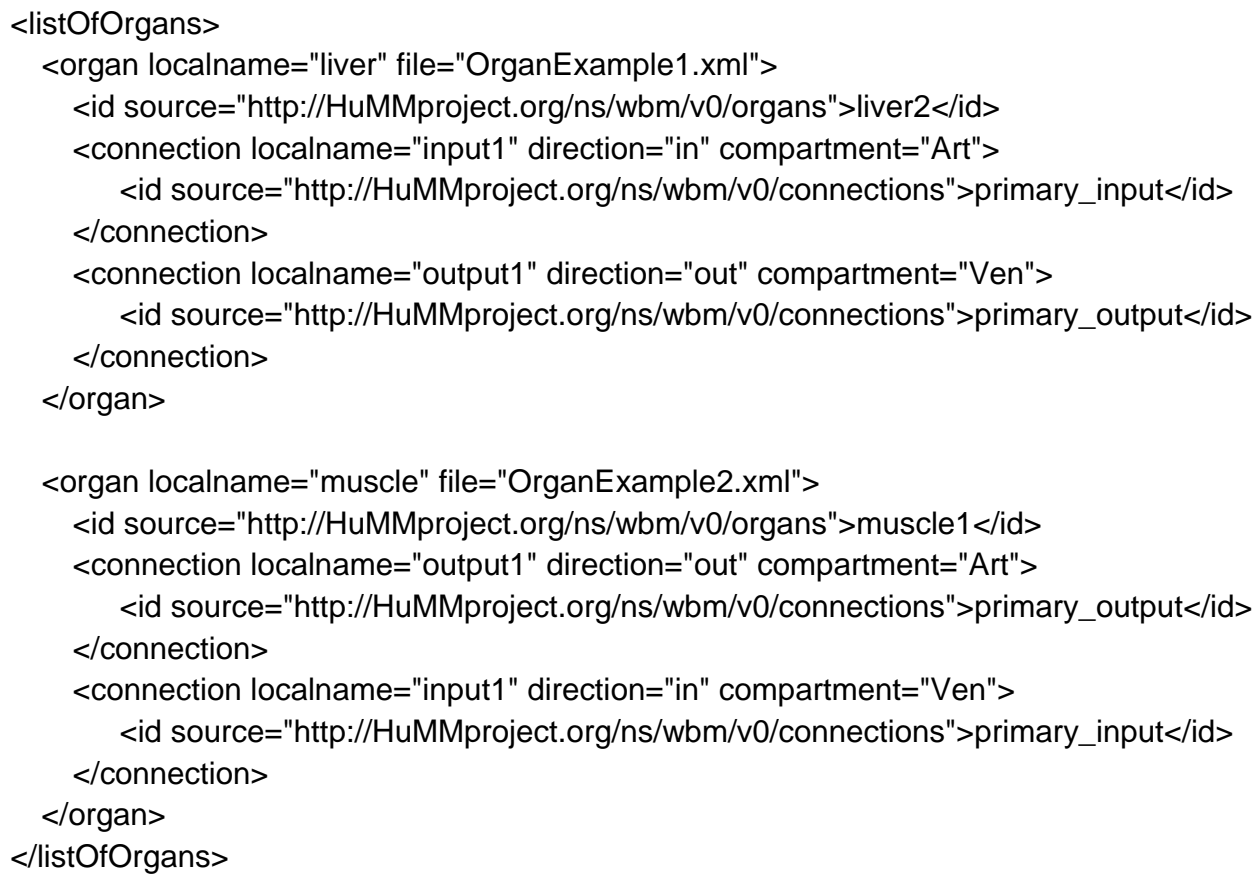

\section{Organ Models}

Organ models are SBML files that can be integrated in a whole-body model. An example organ model file can be found on the project website. All entities in SBML files such as compartments, species, and whole models have an optional annotation field. The model itself has an annotation field denoting the organ being modelled, and the physiological states it fulfills. 


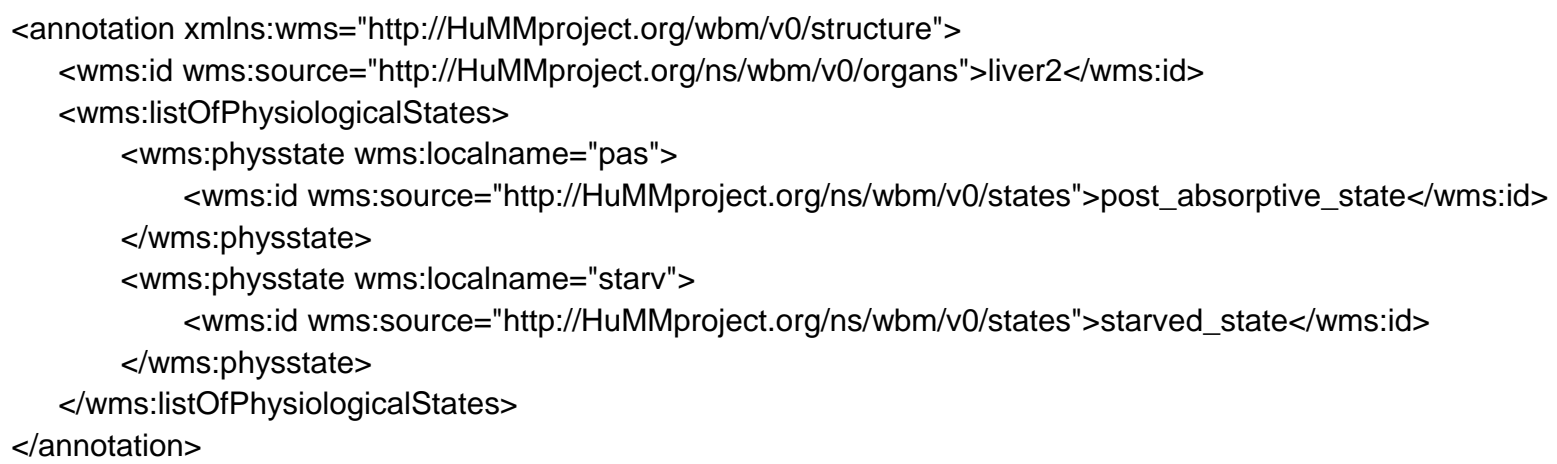

The identifiers of the physiological states and organ type can be cross referenced with the whole-body model description, allowing the model construction to fail at an early point if incompatible models are being combined.

All compartments in the model also include annotation containing information about the compartment volume in the defined physiological states. Connecting compartments also include an identifier (unless the compartment is represented solely by its local name):

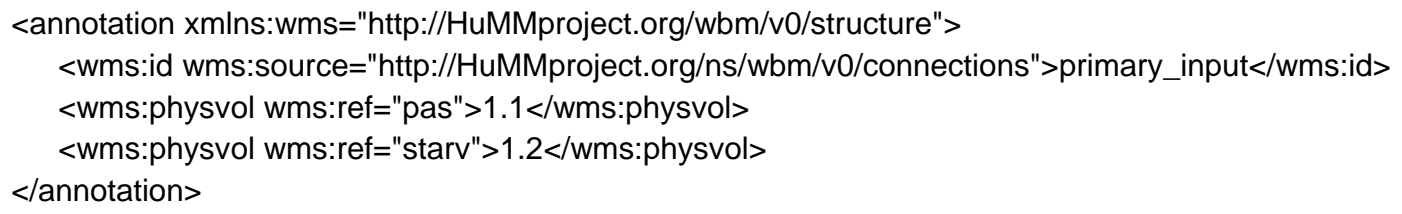

All species contain information about their physiological state concentrations. Species located in the connecting compartments are also represented by their identifier:

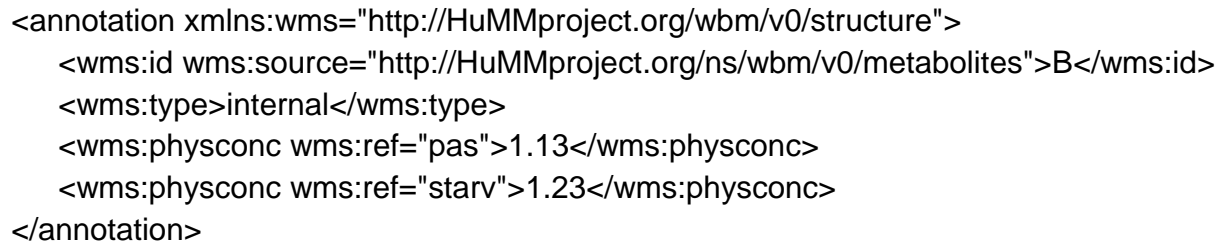

The type has three possible settings storage, external and internal (default value). All species in the connecting (external) compartments are constant in the organ models, and have the boundary condition field set to true.

The storage and external identifiers serve the purpose of linking storage compounds and metabolites in the connecting compartments to their referencing species in the organ model. The organ identifier makes it possible to check that the individual organ models fit the role they are given in the whole body model. 